\title{
Positive FDG-PET/CT of the Pleura Twenty Years after Talc Pleurodesis: Three Cases of Benign Talcoma
}

\author{
Thomas Vandemoortele ${ }^{a, d} \quad$ Sophie Laroumagne ${ }^{a, b} \quad$ Elisa Roca $^{a} \quad$ Olivier Bylicki $^{a}$ \\ Jean-Philippe Dales ${ }^{c}$ Hervé Dutau ${ }^{a}$ Philippe Astoul ${ }^{a}, b$ \\ ${ }^{a}$ Department of Thoracic Oncology, Pleural Diseases and Interventional Pulmonology, Hôpital Nord, ${ }^{b}$ Aix-Marseille \\ University and ' Department of Pathology, Hôpital de la Timone, Marseille, France; ${ }^{d}$ Department of Pulmonology, \\ Centre hospitalier de l'Université de Montréal, Hôpital Notre-Dame, Montréal, Qué., Canada
}

\section{Established Facts}

- Thoracoscopic talc insufflation is used to create chemical pleurodesis for recurring pneumothoraces and pleural effusions.

- The inflammatory reaction to the talc particles has been reported to cause hypermetabolic pleural thickenings on FDG-PET scan up to 5 years after the procedure, but it is not known whether this reaction lasts more than a decade.

\section{Novel Insights}

- Talcomas can present an active inflammatory process, even 20 years after initial insufflation, resulting in a positive FDG-PET scan.

- Such procedures should therefore be mentioned when the clinician orders metabolic imaging.

\section{Key Words}

FDG-PET/CT · Talc pleurodesis · Thoracoscopy ·

Pneumothorax $\cdot$ Pleural inflammation

\section{Abstract}

The FDG-PET (fluorine-18 fluorodeoxyglucose positron emission tomography) scan is used with increasing frequency to investigate pleural abnormalities and to determine the possibility of neoplastic invasion. However, false-positive findings are not uncommon and talc pleurodesis has been reported to cause hypermetabolic pleural thickenings up to 5 years after the procedure. We report the cases of 3 patients ( 2 of whom had a history of asbestos exposure) requiring talc pleurodesis for recurrent pneumothoraces between 1988 and 1990, who were investigated in 2011 for pleural abnormalities. Avid pleural thickening on FDG-PET scan mimicking pleural cancer was found, but this was deemed secondary to

\section{KARGER}

E-Mail karger@karger.com www.karger.com/res (c) 2014 S. Karger AG, Base

0025-7931/14/0873-0243\$39.50/0
Philippe Astoul, MD, PhD

Department of Thoracic Oncology, Pleural Diseases and Interventional Pulmonology Hôpital Nord, Chemin des Bourrely

FR-13326 Marseille cedex 20 (France)

E-Mail pastoul@ap-hm.fr 
the pleurodesis. Talc pleurodesis generates inflammation which promotes pleural adhesions. This inflammatory reaction could decrease with time, as in other inflammatory processes. Since talc is not metabolized by the body, the FDGPET scan can remain positive, most likely because of a foreign-body granulomatous reaction, even 20 years later. It is important to be aware of this possibility and to question patients with pleural abnormalities about past procedures and mention such procedures to the colleagues who are responsible for interpreting metabolic imaging. Follow-up of hypermetabolic pleural lesions attributed to talc pleurodesis is important for the detection of new pleural lesions or neoplastic evolution.

(c) 2014 S. Karger AG, Basel

\section{Introduction}

Talc pleurodesis has been used for more than 50 years in cases of recurring pneumothorax or pleural effusion. Its safety profile and efficacy in clinical practice is well documented nowadays $[1,2]$. It induces an inflammatory reaction which promotes pleural symphysis [3].

Fluorine-18 fluorodeoxyglucose positron emission tomography (FDG-PET) scan is used increasingly as a diagnostic and staging tool in oncology. Its usefulness was first documented in lung cancer, but it is now also one of the imaging tools for pleural diseases [4-7]. However, a major drawback with FDG-PET is that any kind of inflammation can produce high uptake values in al- most any tissue. A result that is positive on FDG-PET usually leads to more invasive procedures to confirm neoplastic disease $[8,9]$.

Case reports have already described high FDG uptake of pleural lesions that could be attributed to talc pleurodesis up to 5 years after the procedure [10].

Here, we describe 3 cases of positive FDG-PET scans conducted 20 years after talc pleurodesis (table 1). Two of the patients had a history of asbestos exposure. We want to alert clinicians to the possibility of benign disease despite the long time interval after the procedure. We recommend that such patients be evaluated by pleural disease specialists, particularly experts in malignant pleural mesothelioma.

\section{Case Reports}

Case 1

A 43-year-old patient was referred to us for a result of pleural thickening on a CT scan. He had worked as an electrician from 1984 until 1994, and had been exposed to asbestos during that time. In 1989, he presented with recurring right pneumothoraces for which he was treated with thoracoscopic talc pleurodesis $(5 \mathrm{~g}$ of calibrated talc).

The patient was asymptomatic and the physical examination was unremarkable. CT scans from 2007 and 2011 were reviewed and these demonstrated a right-sided pleural thickening, with no evolution between the 2 exams.

FDG-PET scan with CT images was performed and showed a multifocal hypermetabolism of the right pleural thickening, predominating at the apex of the lung (SUV max $11 \mathrm{~g} / \mathrm{ml}$ ) (fig. $1 \mathrm{a}-\mathrm{c}$ ). A repeat FDG-PET scan 6 months later was stable, with the same

Table 1. Summary of patient characteristics, FDG-PET and CT scan findings

\begin{tabular}{llll}
\hline Characteristic & Patient 1 & Patient 2 & Patient 3 \\
\hline Age, years & 43 & 46 & 45 \\
\hline Smoking history (pack-year) & none & 10 (stopped 15 years ago) & none \\
\hline Year of talc pleurodesis occurrence & 1989 & 1990 & 1988 \\
\hline Side of pleurodesis occurrence & right & left & bilateral \\
\hline $\begin{array}{l}\text { Hypermetabolism (preferential } \\
\text { location) }\end{array}$ & $\begin{array}{l}\text { upper and medial } \\
\text { pleural space }\end{array}$ & $\begin{array}{l}\text { posterior and lateral } \\
\text { pleural space }\end{array}$ & $\begin{array}{l}\text { posterior and medial } \\
\text { pleural space }\end{array}$ \\
\hline Calcified plaques/nodules & No & Yes & Yes \\
\hline Biopsy & Yes & No & Yes \\
\hline Follow-up duration, months & $6(5$ years of CT scan & 12 & 10 \\
\hline SUV max (g/ml) & follow-up) & 8 & 9 \\
\hline Asbestos exposure & 11 & Yes & No \\
\hline
\end{tabular}


areas of thickening and hypermetabolism (fig. 1d-f). Bilateral hilar lymph nodes were mildly hypermetabolic (SUV max $1.6 \mathrm{~g} / \mathrm{ml}$ ). Endobronchial ultrasound-guided transbronchial node aspiration (EBUS-TBNA) was performed on the hilar nodes. Normal lymphocytes were present, and no cancer cells or granulomas were found in the specimen. Under polarized light, no talc particles were seen.

\section{Case 2}

A 46-year-old patient visited the outpatient clinic for a left pleural thickening on CT-scan and a positive FDG-PET scan carried out in the context of surveillance for asbestos exposure. Indeed, as an editor in a refinery since 1983, he had been exposed to asbestos. In 1990, he had had a left pneumothorax and thoracoscopic talc pleurodesis was performed, but no details were available concerning the amount and type of talc administered. The patient was asymptomatic and the physical examination was unremarkable. A chest CT scan was performed, according to the French Recommendations for Workers with Known Asbestos Exposure; this demonstrated pleural thickenings [11].

FDG-PET scan showed multiple foci of hypermetabolism of the left pleura, corresponding to spontaneously hyperdense pleural thickenings (SUV max $8 \mathrm{~g} / \mathrm{ml}$ ) (fig. 2a-d). A hypermetabolic nodule in the left fissure was also seen on CT images.

\section{Case 3}

A 45-year-old patient was referred with a FDG-PET scan positive for bilateral pleural thickenings. He had had no asbestos exposure. He had had bilateral pneumothoraces in 1988 and had un- dergone talc pleurodesis at that time. The patient also had an HIV infection which was well controlled by antiretroviral therapy. $\mathrm{He}$ was being investigated for abdominal lymph nodes, which had led to the initial FDG-PET scan (fig. 3a, b).

The FDG-PET scan demonstrated areas of pleural thickening with hyperdense areas on both sides. These predominated at the posterobasal regions (SUV $\max 9 \mathrm{~g} / \mathrm{ml}$ ). There were also diffuse small nodules of the parietal pleura, which appeared calcified. An endoscopic ultrasound-guided transesophageal biopsy of a hypermetabolic calcified lesion of the right pleural space at the level of T9-10 showed microgranulomas with a foreignbody reaction centered round refringent microcrystals which corresponded to talc particles (fig. 4). A repeat FDG-PET scan 10 months later did not show any evolution of the pleural thickenings (fig. 3c, d), but a regression of the metabolism and size of the lymph nodes.

\section{Discussion}

Talc pleurodesis was first described by Bethune in 1935, and has been used clinically since 1953 to treat and prevent pneumothorax [12]. Its efficacy to induce pleural adhesions is through parietal and visceral pleural granulomatous inflammation, occurring within $24 \mathrm{~h}$ of the procedure. These changes evolve into a more collagenous re-
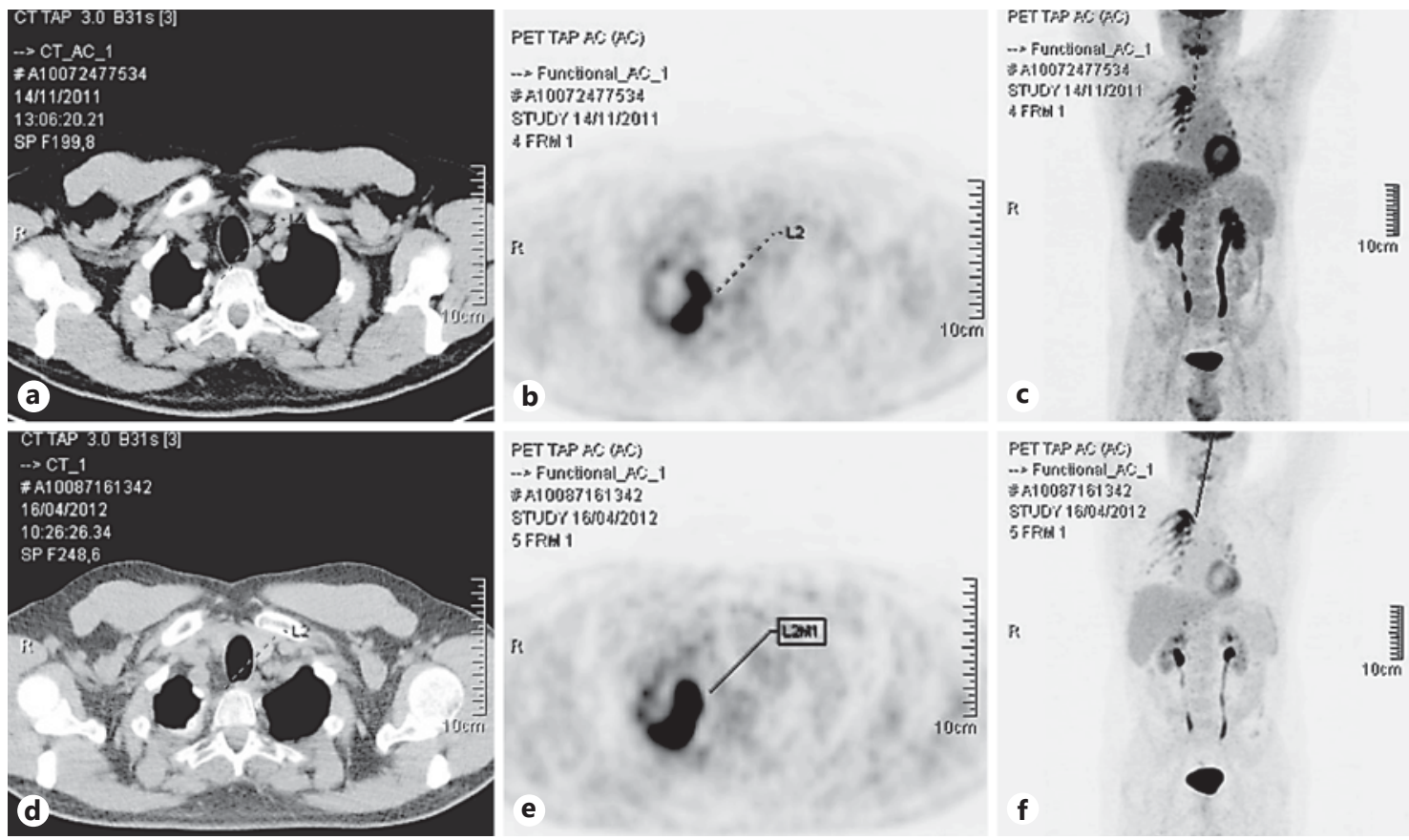

Fig. 1. Imaging studies in a 43-year-old patient with a hypermetabolic thickening in the right upper pleural space secondary to thoracoscopic talc insufflation, performed 22 years ago. At the 6-month follow-up, there was no evolution. November 2011: chest CT scan (a) and FDG-PET scan (b, c). April 2012: chest CT scan (d) and FDG-PET-scan (e, f). 

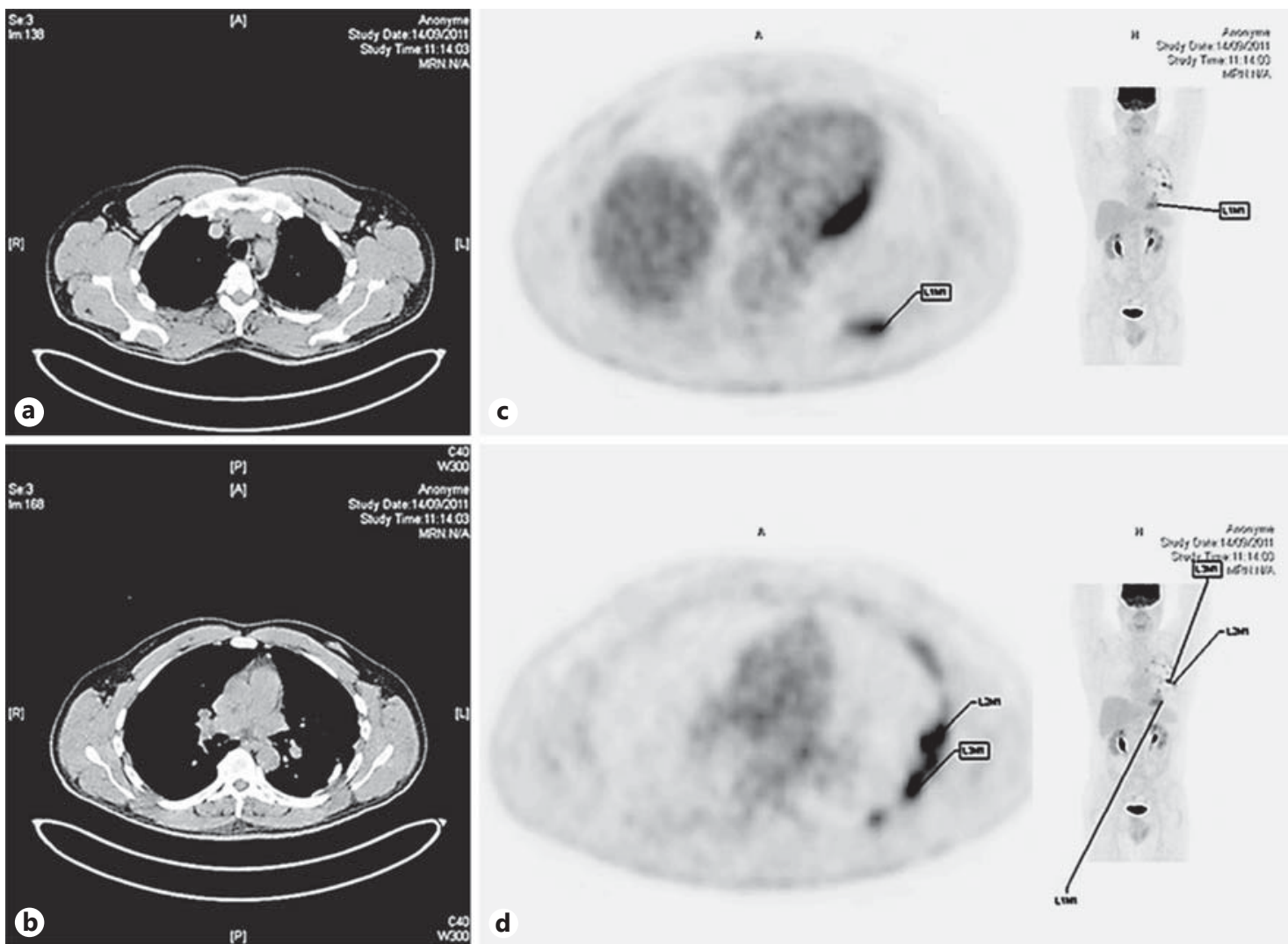

Fig. 2. Chest CT scan (a, b) and FDG-PET scan (c, d) in a 46-year-old patient with left hypermetabolic pleural thickenings secondary to thoracoscopic talc insufflation, performed 21 years ago, compatible with talcomas.
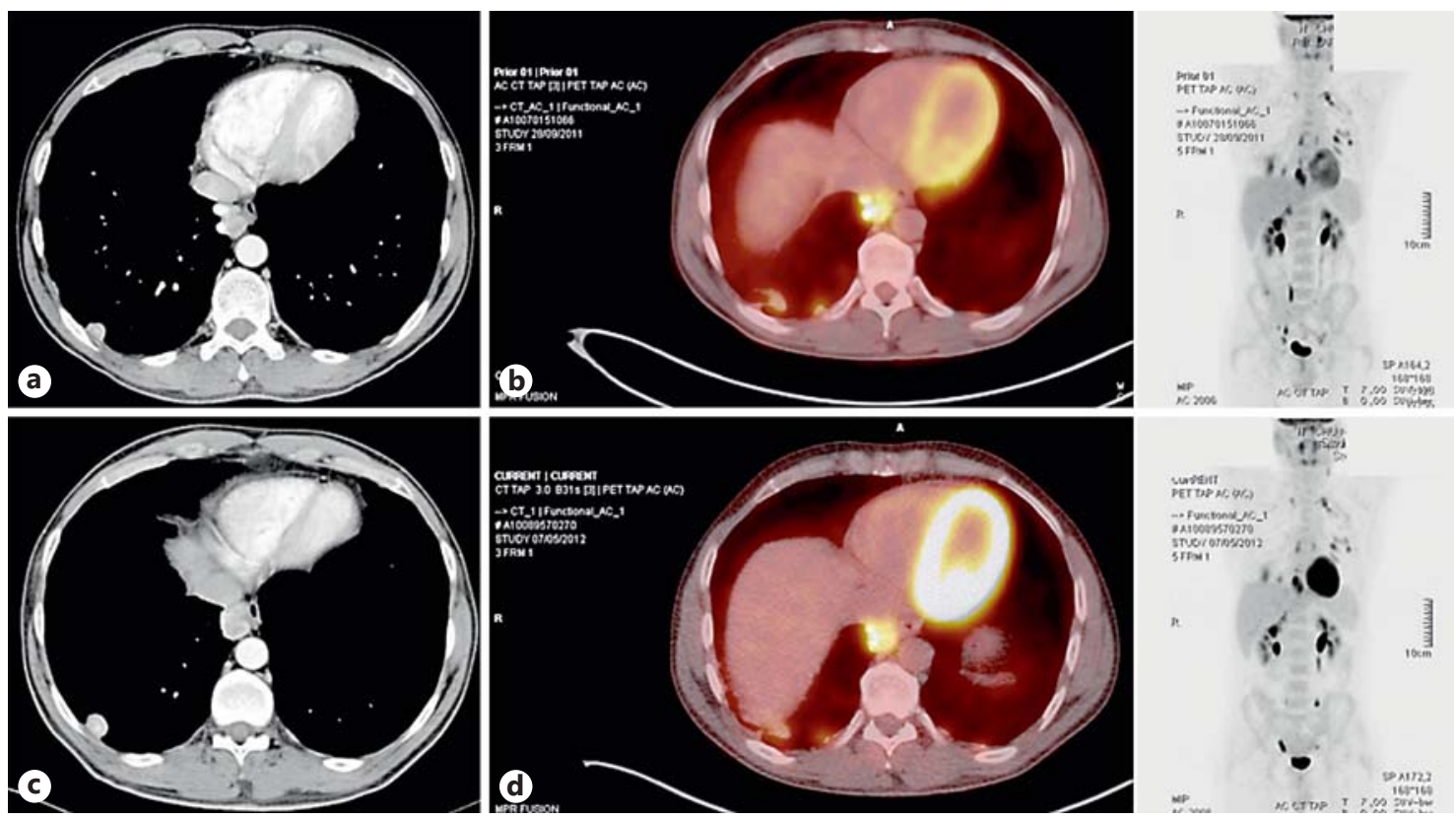

Fig. 3. Imaging studies in a 45-year-old patient with bilateral hypermetabolic pleural thickenings secondary to thoracoscopic talc insufflation, performed 23 years ago. September 2011: chest CT scan (a) and FDG-PET scan (b). May 2012: chest CT scan (c) and FDG-PET-scan (d). 
Fig. 4. HES stain (a) and polarized light (b) microscopy $(\times 100)$ of a transesophageal biopsy demonstrating a microgranuloma (black arrows) centered around refringent microcrystals (red arrows), compatible with talcomas.
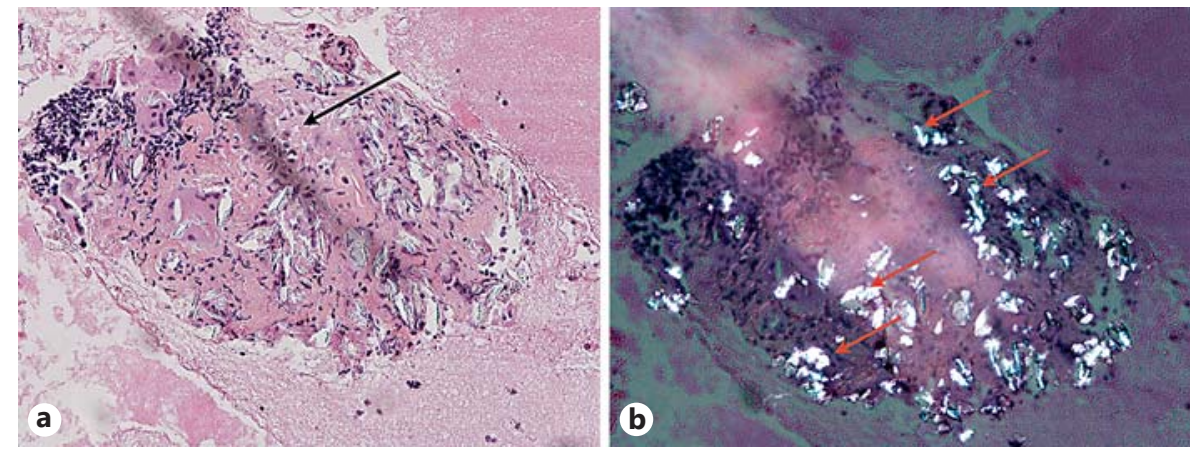

sponse after a few weeks, with talc granulomas. However, after a few months, the reaction usually leads to pleural fibrosis, with sparse talc particles still seen under polarized light $[3,13]$.

While talc-induced acute respiratory distress syndrome was once a concern [14], the safety of talc is now well established when using calibrated talc particles which cannot cross into the systemic circulation or the alveoli $[2,13,15]$. Consequently, talc particles cannot be eliminated easily, and deposits usually occur along the posterior basal aspect of the pleural space $[13,16]$. These deposits can also be found paramediastinally or extend up to the apex or into fissures $[16,17]$.

The appearance of talc pleurodesis on CT reflects these characteristics and it should not be confused with other conditions, such as pleural plaques from asbestos exposure or early-stage malignant pleural mesothelioma or metastatic disease, for example. Murray et al. [16] described variable degrees of pleural thickening and nodularity with residual pleural effusion, most often loculated and located in the posterior portion of the pleural space. Talc deposits present as focal areas of high attenuation $(320 \mathrm{H})$. Talc poudrage seems to produce fine linear deposits, in contrast to larger clusters of high-attenuation material in patients treated by talc slurry. Narayanaswamy et al. [17] reported the same aspect, but also a variant of the split pleura sign, with the presence of talc in both the visceral and parietal pleura separated by an effusion.

The first report of high FDG uptake after talc pleurodesis (talc slurry) was by Murray et al. [18]. Other studies have since described such findings for up to 5 years after talc pleurodesis [10,19-21]. If FDG-PET is performed soon after the procedure, pleural uptake can be normal and then increase with subsequent exams [19-22]. However, none of these studies had enough data to determine whether the amount of talc adminis- tered had any influence on the duration of metabolic activity.

These cases illustrate that the granulomatous reaction to talc can last for at least 20 years, which most likely reflects the fact that talc is not metabolized and cannot be eliminated from the pleural space. The presence of talc particles inducing foreign-body microgranulomas in 1 of our patients supports this claim. Calibrated talc particles did not result in systemic distribution in rats [23], hence the hilar lymph nodes that did not contain talc or granulomas in the other patient.

Correlation between FDG-PET and CT scan images is necessary in order to compare the areas of talc deposits to regions of increased FDG uptake [21]. In patients with increased pleural uptake, monitoring the stability of lesions with increased activity is also important in order to detect new pleural lesions such as metastases or neoplastic evolution. In patients with significant asbestos exposure who are at risk for malignant mesothelioma, diagnostic tools such as transthoracic or thoracoscopic biopsy should be undertaken, especially if they present significant chest-wall pain. However, in patients with no clear asbestos exposure, radiological follow-up could be the initial first step, with a more aggressive approach for progressive lesions.

\section{Conclusion}

Talc pleurodesis induces a granulomatous reaction that can last more than 20 years. This can result in high FDG uptake and hypermetabolism. Clinicians should be aware of this possibility and question patients about past pleural procedures. Follow-up of hypermetabolic pleural lesions attributed to talc pleurodesis is important for the detection of new pleural lesions. 


\section{References}

1 Janssen JP, Collier G, Astoul P, et al: Safety of pleurodesis with talc poudrage in malignant pleural effusion: a prospective cohort study. Lancet 2007;369:1535-1539.

$>2$ Bridevaux PO, Tschopp JM, Cardillo G, et al: Short-term safety of thoracoscopic talc pleurodesis for recurrent primary spontaneous pneumothorax: a prospective European multicentre study. Eur Respir J 2011;38:770-773.

$\checkmark 3$ Rodriguez-Panadero F, Montes-Worboys A: Mechanisms of pleurodesis. Respiration 2012;83:91-98.

4 Orki A, Akin O, Tasci AE, et al: The role of positron emission tomography/computed tomography in the diagnosis of pleural diseases. Thorac Cardiovasc Surg 2009;57:217-221.

5 Ayres J, Gleeson F: Imaging of the pleura. Semin Respir Crit Care Med 2010;31:674-688.

-6 Basu S, Saboury B, Torigian DA, Alavi A: Current evidence base of FDG-PET/CT imaging in the clinical management of malignant pleural mesothelioma: emerging significance of image segmentation and global disease assessment. Mol Imaging Biol 2011;13:801811.

7 Makis W, Ciarallo A, Hickeson M, et al: Spectrum of malignant pleural and pericardial disease on FDG PET/CT. AJR Am J Roentgenol 2012;198:678-685.

$\checkmark 8$ Carretta A, Landoni C, Melloni G, et al: 18FDG positron emission tomography in the evaluation of malignant pleural diseases - a pilot study. Eur J Cardiothorac Surg 2000;17: 377-383.
9 Kramer H, Pieterman RM, Slebos DJ, et al: PET for the evaluation of pleural thickening observed on CT. J Nucl Med 2004;45:995998.

10 Hemdan Abdalla AM, White D: A 29-yearold woman with a remote history of osteosarcoma and positron emission tomographypositive pleurally based masses. Talcomas secondary to prior talc pleurodesis. Chest 2008;134:640-643.

-11 Rolland P, Gramond C, Lacourt A, Astoul P, et al: Occupations and industries in France at high risk for pleural mesothelioma: a popula tion-based case-control study (1998-2002). Am J Ind Med 2010;53:1207-1219.

12 Smith FR: Talc poudrage treatment of recurrent and chronic spontaneous pneumothorax. Northwest Med 1953;52:937-938.

13 Tschopp JM, Rami-Porta R, Noppen M, Astoul P: Management of spontaneous pneumothorax: state of the art. Eur Respir J 2006;28: 637-650

14 Sahn SA: Talc should be used for pleurodesis: pro/con editorials. Am J Respir Crit Care Med 2001;163:2023-2026.

15 Milanez de Campos JR, Vargas FS, Werebe EC, et al: Thoracoscopy talc poudrage: a 15 year experience. Chest 2001;119:801-806.
16 Murray JG, Patz EF Jr, Erasmus JJ, Gilkeson RC: CT appearance of the pleural space after talc pleurodesis. AJR Am J Roentgenol 1997; 169:89-91.

17 Narayanaswamy S, Kamath S, Williams M: CT appearances of talc pleurodesis. Clin Radiol 2007;62:233-237.

18 Murray JG, Erasmus JJ, Bahtiarian EA, Goodman PC: Talc pleurodesis simulating pleural metastases on 18F-fluorodeoxyglucose positron emission tomography. AJR Am J Roentgenol 1997;168:359-360.

19 Kwek BH, Aquino SL, Fischman AJ: Fluorodeoxyglucose positron emission tomography and CT after talc pleurodesis. Chest 2004;125: 2356-2360.

20 De Weerdt S, Noppen M, Everaert H, Vincken W: Positron emission tomography scintigraphy after thoracoscopic talcage. Respiration 2004;71:284.

21 Weiss N, Solomon SB: Talc pleurodesis mimics pleural metastases: differentiation with positron emission tomography/computed tomography. Clin Nucl Med 2003;28:811-814.

22 Nguyen NC, Tran I, Hueser CN, Oliver D, Farghaly HR, Osman MM: F-18 FDG PET/ CT characterization of talc pleurodesis-induced pleural changes over time: a retrospective study. Clin Nucl Med 2009;34:886-890.

-23 Fraticelli A, Robaglia-Schlupp AE, Riera H, Monjanel-Mouterde S, Cau P, Astoul P: Distribution of calibrated talc after intrapleural administration: an experimental study in rats. Chest 2002;122:1737-1741. 